\title{
Listening to Our Collections: Preserving Records of University-Based Educational Radio Stations in Campus Archives
}

Erik A. Moore and Rebecca Toov

University Archives, University of Minnesota Libraries, University of Minnesota, Minneapolis, USA

\begin{abstract}
University-based educational stations transmitted programming to local audiences throughout the U.S. Surviving records remain in the custody of university archives but remain unavailable due to the complicated nature of radio collections and their audio components, placing them at risk of loss. Using the University of Minnesota station KUOM as a case study, this paper documents archivists' successful advocacy for the processing and preservation of historical radio materials. The authors offer reflections on broader strategies that archivists may employ to help process and digitize materials documenting the history of university-based radio within their collections.
\end{abstract}

Keywords: university radio; archival description; audio archives

\section{Published as}

Moore, Erik A. \& Rebecca Toov (2020) "Listening to Our Collections: Preserving Records of University-Based Educational Radio Stations in Campus Archives." Journal of Archival Organization 17, nos. 1-2: 38-53.

DOI: 10.1080/15332748.2020.1754707 


\section{Introduction}

In 2012, the Library of Congress National Recording Preservation Plan declared, "Most of the nation's audio collections are stored under conditions that contribute to their deterioration" and that they "must be digitized within the next 15 or 20 years before further degradation makes preservation efforts all but impossible." ${ }^{1}$ Funding agencies and archival institutions responded with applications and project proposals to preempt the degradation through digital reformatting of audio recordings. However, many faced difficulties in assessing their collections due to a lack of item-level metadata and intellectual control over the audio collections as a whole. In order to respond to the call to preserve audio recordings, institutions had to "conduct comprehensive item-level appraisals of their audio holdings to make strategic and timely preservation reformatting decisions."

A subset of these audio holdings resides in university archives and special collections at universities and colleges as part of their campus-based radio station collections. Public broadcasting in the United States originated from experimental stations at public land-grant universities with their connection to extension services "as they experimented with different uses for the new technology, not only with serious informational and educational broadcasting but also with entertainment programming."3 The university-based stations emphasized programming that took their audience into account to build a sense of local community and a commitment to public service as a standard for what would become the basis of non-profit radio. ${ }^{4}$

\footnotetext{
${ }^{1}$ National Recording Preservation Board of the Library of Congress, Library of Congress National Recording Preservation Plan: CLIR Publication 156 (Washington DC: Council on Library and Information Resources, 2012), 2. Accessed March 18, 2020. https://www.loc.gov/programs/nationalrecording-preservation-plan/publications-and-reports/.

${ }^{2}$ Ibid., 21.

${ }^{3}$ Land-grant universities received congressional funding through a series of laws in the $19^{\text {th }}$ and early $20^{\text {th }}$ centuries in the United States to provide agricultural education and general extension services, or outreach education, directed for the citizens of the state. See Hugh Richard Slotten, Radio's Hidden Voice: The Origins of Public Broadcasting in the United States (Chicago: University of Illinois Press, 2009), 9-10. This is also supported by Robert J. Blakely's To Serve the Public Interest: Educational Broadcasting in the United States (Syracuse University Press, 1979), 53-54.

${ }^{4}$ Slotten, Radio's Hidden Voice, 41.
} 
This article demonstrates that the inclusion of archival processing of university administrative records and personal papers of pioneering staff involved in the production and programming of campus-based educational and non-profit radio is a core element of the overall preservation of radio history. While timely efforts to digitally convert and preserve audio recordings currently on deteriorating or damaged media is an absolute necessity, prefacing the digital reformatting with the processing of archival records aids in the survey of media collections, creation of item-level metadata, and solicitation of funds to pay for their digital conversion and preservation. This expanded access to documentation provides archivists and curators more information to define and describe the audio recordings, the individuals that created the programs, and the network of stations that distributed the content. This case study presents an approach that first focuses on the processing of archival records as part of a holistic methodology that includes the item-level description of recordings and plans for digital reformatting. This strategy best prepares these at-risk materials for successful digitization proposals and allows for a more comprehensive understanding of the history of university-based radio that can be applied to other broadcast media digitization projects and points of access through finding aids, online sharing, and repurposing of the content into new modes of delivery.

What follows is an overview of the processing project, including the project design, descriptive work, and arrangement of the collection. It leads to a discussion of two subsequent digitization projects that, in turn, contribute to an on-going, iterative description of the archival materials and audio recordings. The final section considers the uses of a radio collection benefiting from this holistic approach.

\section{Processing the KUOM collection}

In 2015, the University of Minnesota (UMN) Archives began a twelve-month processing project to organize and describe over 160 cubic feet of administrative materials of the University of Minnesota Radio and Television Broadcasting records, known informally as the KUOM collection. Originally licensed on January 13, 1922 as WLB, the University of Minnesota radio station, KUOM, is the first and oldest radio station in Minnesota and the tenth oldest continuously operating station in the United States. ${ }^{5}$ As part of the

\footnotetext{
${ }^{5}$ Andrew Marlow's thesis, 9XI/WLB/KUOM: Pioneering Radio Station (University of Minnesota, 1996) is the singular overview of the history of KUOM.
} 
University's General Extension Division, the station utilized existing University resources to extend the educational and outreach activities of the University beyond campus and throughout the state by radio transmission. The University eliminated funding for KUOM during a restructuring and reallocation process in 1991. In 1993, the University turned over the license and call letters to the student-run station WMMR; the station changed format and rebranded as Radio K, which continues today. ${ }^{6}$ The collection consists of Federal Communications Commission applications; staff correspondence and reports; minutes of the Radio Policy Committee; daily program logs; program development files and production scripts; grant files for the Corporation for Public Broadcasting (CPB), and records related to the proposed merger of KUOM and Minnesota Public Radio (MPR). ${ }^{7}$ The project also reviewed and described over 11,000 reel-to-reel tapes, which contain as-aired broadcasts and unedited recordings totaling 635 linear feet.

The bulk of the collection - administrative records and audio recordings - arrived at the UMN Archives between October 1993 and March 1994. Physical and intellectual access was nearly non-existent for twenty years. There were no box listings or descriptions of the administrative records and there were only minimal, incomplete lists that described the reel-to-reel tapes. The nominal information that was available reflected the "as-is" state of the materials.

\section{Project design}

The project set out to process and make available an online description of the collection. It intended to survey the collection, re-house materials in new boxes and folders as needed, physically arrange contents sparingly, and describe the collection contents in an encoded online finding aid. Project staff applied the "minimal processing" methodology

${ }^{6}$ WMMR, the student-run station which operated out of separate facilities in the student union, was established in 1946. In March 1991, the University of Minnesota Board of Regents voted on a restructuring plan that would eventually cease KUOM radio operations. As a result, the license for KUOM was turned over to WMMR on October 1, 1993 and the educational station switched to a modern rock format and adapted a new moniker - Radio-K.

${ }^{7}$ Grant funding for the year-long project was provided by the State of Minnesota from the Arts and Cultural Heritage Fund as administered by the Minnesota Historical Society. Erik Moore served as Principal Investigator and Rebecca Toov was the project archivist. 
described in the article "More Product, Less Process: Revamping Traditional Archival Processing." 8 A benefit of this method is that the efficiency gained through minimal techniques allow for more detailed work to be conducted where appropriate. Similarly, Kathleen Roe's work on arrangement and description also influenced the project's flexibility when describing different series within the same collection. ${ }^{9}$

Using these professional practices as a guide, the project archivist processed the collection as two major series based on the existing physical organization of the materials. Minimal processing of the administrative records afforded enough time within the twelvemonth grant period to create a detailed inventory for the 11,000 trayed audio reels. The decision to create item-level descriptions for this quantity of materials was not taken lightly. Project staff reasoned that playback of the audio recordings would not be possible nor desirable during the description process. Thus, descriptive information and technical metadata (e.g., tape length, playback speed, run time, tape manufacturer, etc.) easily discerned from labels on the tape box or as inserts provided the essential item-level metadata for the audio recordings. This offered three benefits. First, it provides better description and keyword access to the recordings for archives staff and researchers. Previous requests for audio content were for specific programs, individuals, and/or events. Describing the audiotapes at the series level would limit discovery. Second, describing each recording in hand allows for the archivist to record and identify preservation concerns including mold or other deterioration that may need to be addressed before a reformatting project. Finally, an item-level description that includes technical metadata about the recording aids review of the collection for digitization. Technical metadata could be used to estimate the length of recordings, if run time is not indicated on the reel or box label, which allows for a better estimate of the time required for digital conversion. This approach followed the advice offered by Greene and Meissner that "some series may warrant more than the minimum effort" based on "clearly demonstrable business reasons." ${ }^{10}$ Better researcher access to specific recordings and the ability for staff

\footnotetext{
${ }^{8}$ Mark A. Greene and Dennis Meissner, "More Product, Less Process: Revamping Traditional Archival Processing," The American Archivist, 68, no. 2 (Fall/Winter 2005).

${ }^{9}$ Kathleen Roe, Arranging and Describing Archives and Manuscripts (Chicago: Society of American Archivists, 2005), 71-72.

${ }^{10}$ Greene and Meissner, "More Product, Less Process," 240.
} 
to assess the viability of a potential large-scale digitization effort were the demonstrable business reasons.

\section{Description}

The history of KUOM radio is embedded in the University's institutional history. In some cases, the use of related archival sources separate from the KUOM collection expedited the description process. Knowledge about station technology and broadcasting activity is found in departmental correspondence and related papers of faculty members in electrical engineering. A portion of the General Extension Division archival collection documents station activities and include correspondence files of the station's long-time director, Burton Paulu. Selected materials contained within the Office of the President records further document the administrative development and national regulatory matters of WLB/KUOM. Another significant related collection is the Betty Girling papers. Girling began at the station in 1940 as a student and would later serve as program director for the Minnesota School of the Air from 1945 until her death in 1979. The papers provide significant documentation on the role of a program manager in educational radio to include program development and promotion, script writing, and participation in professional organizations in the fields of education and broadcasting.

Understanding that early efforts in experimental and educational radio programming found a natural home in the outreach missions of land-grant universities; these institutions in turn created consortiums such as the National Association for Educational Broadcasters (NAEB) to expand their cooperative outreach. Thus, collection related content and description for one university station is likely to be found at other institutions. Burton Paulu served in most major leadership positions for the NAEB. Paulu's national affiliation resulted in the dissemination of a wide variety of original programs written and produced by WLB/KUOM staff through the NAEB network of noncommercial educational radio stations throughout the United States. While not consulted for this project, the records for NAEB are split between the Wisconsin Historical Society (WHS) on the University of Wisconsin-Madison (UW-Madison) campus and the University of Maryland (UMD) with the administrative records held at WHS and 5,063 
audiotape reels at UMD. ${ }^{11}$ Today, those separate collections are undergoing a digital reunification as part of a National Endowment for the Humanities (NEH) award at the direction of Stephanie Sapienza (UMD) with Co-PI Eric Hoyt (UW-Madison). ${ }^{12}$

In addition to using these related archival collections, source material found in the University of Minnesota's institutional repository assisted in understanding context and securing descriptions of radio programs. The University's institutional repository, the University Digital Conservancy, which serves as the digital arm of the UMN Archives, includes digital copies of institutional publications including catalogs, press releases, newsletters, administrative reports, and meeting agendas and minutes. Keyword searching these previously digitized materials for program titles and topics allowed for brief descriptions to be included in the scope and content notes for the radio programs rather than listening to hundreds of hours of audio recordings or synthesizing the related documentation and creating original scope notes.

\section{Arrangement}

Although the administrative records and audio recordings were processed separately as distinct series due to their physical organization, project staff approached the intellectual arrangement and description of collection contents holistically. When creating the finding aid for the collection, archives staff chose to incorporate descriptions of individual audio reels as sub-series listed alongside the administrative records at the radio program series level. The decision to integrate administrative records and audio recordings under the same series was three-fold. First, it provides a researcher reviewing a specific program contextual information regarding the availability of audio recordings. Previous researcher behavior indicated that requests were for audio from a specific radio program and show. This grouping allows a researcher to quickly survey all of the recordings associated with a radio program for additional context. Second, it allows for the grouping of all relevant

\footnotetext{
${ }^{11}$ National Association of Educational Broadcasters records, 1925-1977 (bulk 1950-1970), WHS; National Association of Educational Broadcasters (NAEB) audio tapes, 1952-1968, University of Maryland Libraries (UMD), Special Collections and University Archives.

12 Stephanie Sapienza, "MITH receives NEH grant for 'Unlocking the Airwaves: Revitalizing an Early Public and Educational Radio Collection'," Maryland Institute for Technology in the Humanities
} (MITH) Blog, May 10, 2018. Accessed March 30, 2020. https://mith.umd.edu/mith-receives-nehgrant-for-unlocking-the-airwaves-revitalizing-an-early-public-and-educational-radio-collection/. 
records - paper and audio - for a radio series, and emphasizes that all records, regardless of material type, are essential for the description of a radio program.

An example of this approach is the Minnesota School of the Air program Your Health and You, a program on the importance of health and health practices in daily life produced for a school-aged audience. The finding aid presents the program series as a sub-series with a list of relevant schedules and correspondence from the administrative records. It also includes a sub-sub-series for audio recordings of the program (Figure 1).

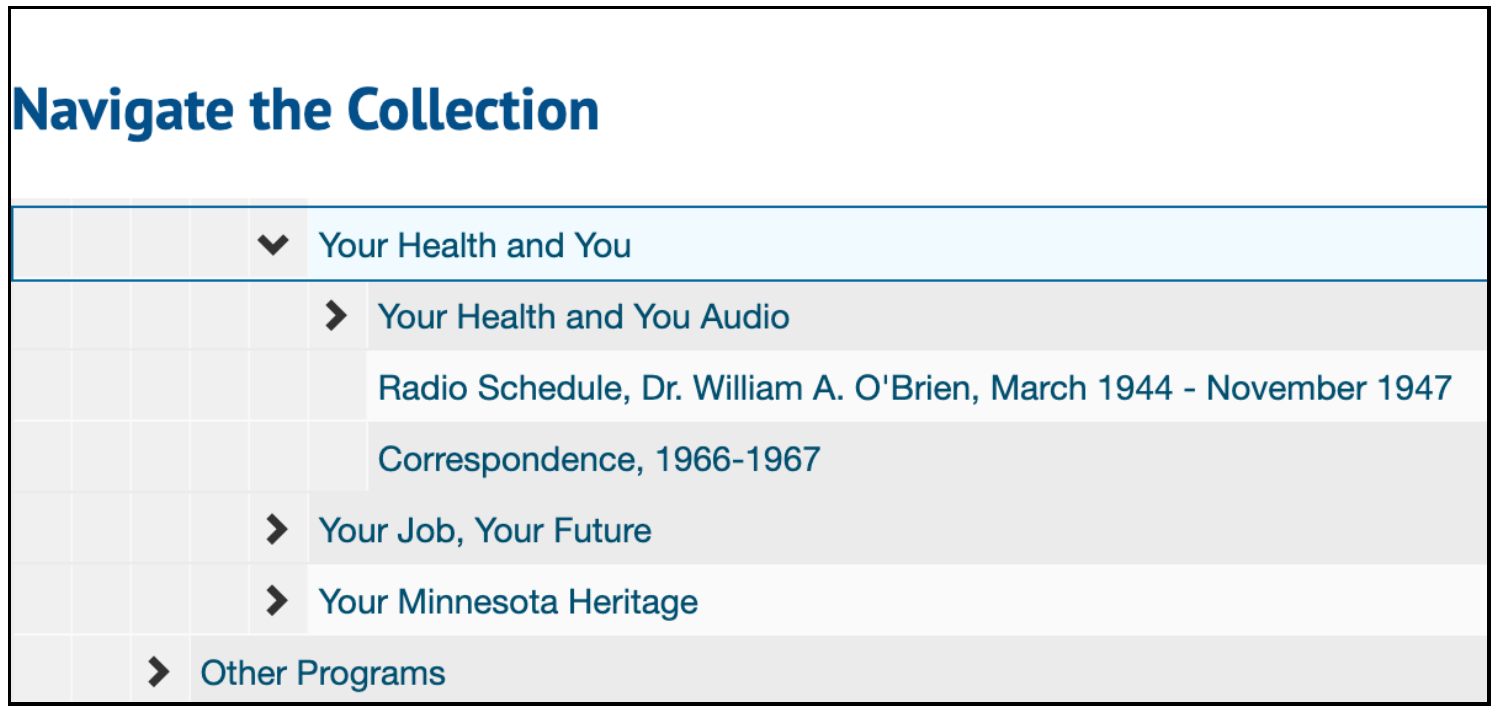

Figure 1. Screen capture of finding aid for the University of Minnesota Radio and Television Broadcasting records, UMN Archives. Detail for the sub-series Your Health and You and subsequent audio series. Available at https://archives.lib.umn.edu/repositories/14/archival_objects/749001. Courtesy University of Minnesota (UMN) Libraries.

In this audio sub-sub-series, each associated audio recording includes the descriptive and technical metadata logged during the item-level review process including a transcription of the engineer cue sheet (caption), extent (1 Reel), size (5-inch reel/600 ft), duration (14 minutes and 15 seconds), manufacturer information (3M Scotch Brand Recording Tape No. 175), and technical playback information (speed: 7 1/2) (Figure 2). 


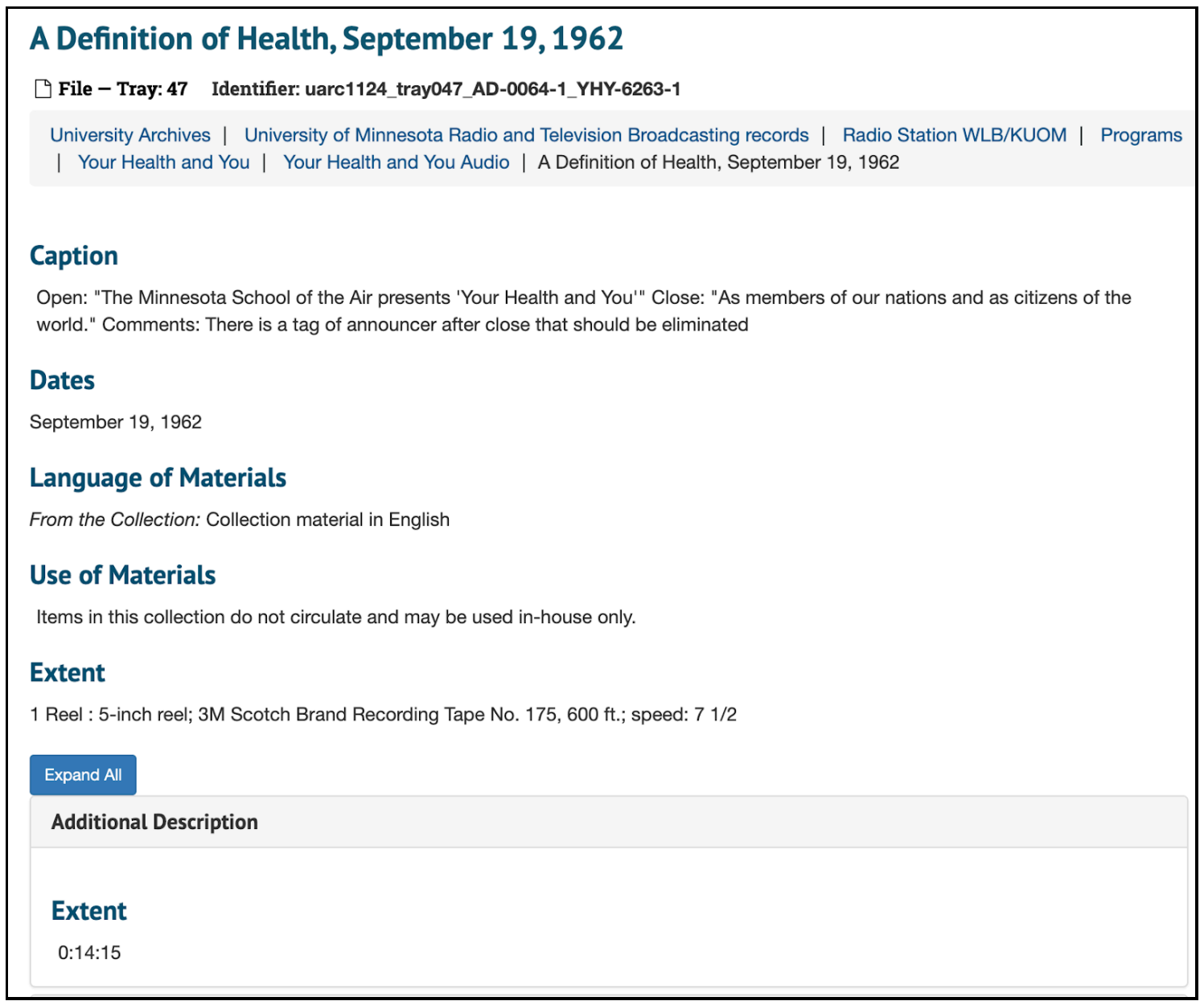

Figure 2. Screen capture of finding aid for the University of Minnesota Radio and Television Broadcasting records, UMN Archives. Detail for individual recording description including technical metadata as part of sub-series Your Health and You. Available at https://archives.lib.umn.edu/repositories/14/archival_objects/962579. Courtesy UMN Libraries.

Finally, including audio recordings as part of the program sub-series provides content in cases where no textual materials exist for a program in the administrative records. Thus, in some instances, the audio recordings serve as the only evidence for the program. For example, the radio program Indian News was a five-minute segment airing weekday afternoons beginning in the early 1970s. Partially funded by the Corporation for Public Broadcasting (CPB), the news show includes in-studio reporting and in-the-field interviews conducted by members of the Native American community. While there is documentation in the collection for the planning and funding of the program through the $\mathrm{CPB}$, no documentation for the as-aired radio programs outside of the audio recordings is available. 
Greene and Meissner remind readers of Roe's requirements for good description including "to represent the context of the materials (provenance and interrelationships), their physical characteristics, and their informational content."13 Instead of separating material types into distinct series, the decision to intellectually arrange the audio recordings as part of the program administrative records allows for the finding aid to maximize these aims while also impressing upon the user the contextual value of the audio material despite limited access to the media. This arrangement also aids in the surveying needed to make strategic decisions regarding preservation and digital reformatting.

\section{Next step: Reformatting audio}

This newly acquired contextual information about KUOM, along with detailed information for each recording including program title, air date, run length, and size of media, allowed for the UMN Archives to clearly articulate the scope of their collection and prioritize audio recordings for digital reformatting. As a result, the UMN Archives received two separate grants to fund the digitization of an estimated 5,000 reel-to-reel tapes. ${ }^{14}$ The first digitization grant, an award of $\$ 105,419$ from the Minnesota Arts and Cultural Heritage Fund administered by the Minnesota Historical Society in 2016, provided for the digital reformatting of 2,439 individual radio programs on 2,339 reel-toreel tapes. ${ }^{15}$ The second digitization grant awarded in 2019 was for $\$ 44,000$ from Recordings at Risk program of the Council on Library and Information Resources (CLIR). This second proposal plans to digitize nearly 2,500 reel-to-reel audiotapes. ${ }^{16}$

The availability of an item-level metadata integrated with the fully processed administrative records provided staff the tools to appraise the appropriateness of the

\footnotetext{
${ }^{13}$ Greene and Meissner, "More Product, Less Process," 247.

${ }^{14}$ Emily Vinson demonstrates a similar benefit of item-level description to acquire grant funding for audio-visual digital conversion projects in her article "Reassessing A/V in the Archives: A Case Study in Two Parts," The American Archivist 82, no. 2 (Fall/Winter 2019): forthcoming.

${ }^{15}$ Grant funding for the year-long project, "Preservation of Minnesota's Radio History: An Audio Digital Conversion and Access Project," was provided by the State of Minnesota from the Arts and Cultural Heritage Fund as administered by the Minnesota Historical Society. Erik Moore served as Principal Investigator and Karen Obermeyer-Kolb and Hannah O’Neill served as project archivists.

16 "U Libraries receives \$44,000 for radio digitization," From the Archivist, October 23, 2019. https://www.continuum.umn.edu/2019/10/u-libraries-receives-44000-for-radio-digitization/.
} 
analog audio for large-scale digitization projects. In her work on audio appraisal, Christopher Ann Paton discusses the differences of audio appraisal from textual documents and outlines three primary criteria: medium specificity, form, and audio quality. For medium specificity, Paton explains that this criteria "asks whether the information captured on the recording benefits by being in audio rather than textual or other form." ${ }^{17}$ A considerable number of the KUOM recordings include scripted dramas, interview format programs, and documentary reporting. Although scripts for many of the programs are available in the administrative records, the audio recordings provide additional context not otherwise available. The recordings hold an informational value not originally intended by the creators. This includes word choices, intonations, and dialects that demonstrate a speaker's familiarity or point of view as well as audio documentation of background noises. This medium specificity can further place the recording in context for the researcher. As an example, from a live recording of a campus protest in 1972 the listener can hear the heavy breathing, coughing, and gasping for air of a reporter being surrounded by tear gas. It is a raw scene that brings the listener into the moment. ${ }^{18}$

Media reformatting is a necessity in audio preservation. Digitization of analog formats is a logical step in the reformatting chain as was refreshing one analog form to another before being surpassed by digital. ${ }^{19}$ Paton notes that "Format rarity and obsolescence contribute to high processing and access costs, while media that deteriorate quickly lead to high preservation costs... must eventually be incorporated into evaluation of the 'costs of retention' of the materials." 20 This evaluation of costs places a greater emphasis on individual item appraisal and description than would be applied to textual records.

\footnotetext{
${ }^{17}$ Christopher Ann Paton, "Appraisal of Sound Recordings for Textual Archivists," Archival Issues 22, no. 2 (1997): 125.

${ }^{18}$ Hannah O’Neill, “Eight Days in May,” U of M Radio on Your Historic Dial (podcast blog), May 23, 2017. Accessed March 30, 2020. https:/www.continuum.umn.edu/2017/05/eight-days-may/. The entry for this audio recording in the KUOM collection finding aid is available at https://archives.lib.umn.edu/repositories/14/archival_objects/1030576.

${ }^{19}$ Christopher Ann Paton, "Preservation Re-Recording of Audio Recordings in Archives: Problems, Priorities, Technologies, and Recommendations," The American Archivist 61 (Spring 1998): 207.

${ }^{20}$ Paton, "Appraisal of Sound Recordings for Textual Archivists," 125.
} 
Audio quality, which is impossible to gauge in formats for which there is no longer equipment for playback, comes into consideration at the point of quality control immediately after digitization. Here, the quality of the digitally reformatted file will determine if it warrants the additional cost of retention or if the transferred recording is considered end-of-life and no longer viable to provide informational value.

In preparing the digitization proposals, project staff leveraged the availability of the administrative records to further support Paton's method of audio appraisal. The extensive documentation of the radio programs available in the administrative records proved essential in understanding media specificity and preparing for reformatting and retention costs. The administrative records for radio programs and series make a semblance of a whole of all of the individual item descriptions. It allows the archivist and funding organizations to see the totality of the resources when making a case for digitization costs and funds for long-term preservation. Finally, the appraisal of the audio reels benefited from the informational value of textual documentation provided with the audio reels including handwritten labels, cue sheets, and even manufacturer details, which allowed for better estimates for the length of recordings and production quality. ${ }^{21}$ As a source of technical metadata, these sources predict a foundation for audio quality through information the engineer sought to capture about the recording.

\section{Enriching metadata}

The description and intellectual arrangement of the KUOM collection benefits from an iterative descriptive approach as the collection is continually used and evaluated for research, reference services, digitization, and promotion. As Roe notes, "records do not need to be described once and for all time. Once a core description is completed, a priority for further description can be determined and the description expanded as researcher demand, resources, and time permit."22 This further description came from archives staff reviewing the administrative records and listening to the digitized audio recordings. Through this continuing effort, archives staff discovered their endeavors to gain intellectual control over the collection echoed initial attempts undertaken by the record

\footnotetext{
${ }^{21}$ Robert Pruter makes a similar argument for the evidentiary value of labels for commercially produced recording labels. See "Words and Music: Understanding the Value of Textual Content on Commercial Sound Recording Labels," Archival Issues 25, nos. 1 \& 2 (2000): 58-59.

22 Roe, Arranging and Describing Archives and Manuscripts, 72.
} 
creators themselves. This further informed our description efforts, as it revealed greater insight in the life cycle of the materials.

In a 1974 summary report of station activities, a station traffic manager expressed frustration with "the improper marking of tapes," and suggested the need for improved and consistent administrative procedures: "I provide slips of paper with spaces for information expressly for the purpose of identifying tapes by putting these slips, filled out with identifying information, into the boxes. There are producers who scratch inaudibly on the backs of tapes and those that tape things on the front and that sometimes get torn off..."23 This sentiment was recognized by the archivists charged with compiling tape inventories and preparing metadata for digitization who relied upon existing - often illegible, undated, and generic - notations written on the outside of tape boxes or cue sheet inserts. This occurrence is exemplified with a series of tapes labeled "Student hour," or "The Hour," numbered \#9, \#10, etc. which were incorrectly assumed to be affiliated with student-run station WMMR based on such notations. It wasn't until after listening to the programs - long after the conclusion of the grant project - that further research inspired correction. Though students who were affiliated with WMMR contributed to the programs, "The Hour," a 60-minute student-produced program, which aired on KUOM Saturday afternoons from 1972-1975, was made possible through funding from a Corporation for Public Broadcasting Community Service grant, indicating it was a KUOM production, not WMMR. This correction resulted from listening to the audio content of the recordings and consulting program logs and grant reports in the administrative records that corroborated these details.

Listening also enables staff to add details to the descriptive metadata that includes the identification of speakers, segment topics, and issues discussed. However, in practice, the activity of listening is time-consuming, on-going, and often extra-curricular, conducted by current staff with knowledge of the collection and project history. This practice of iterative description for improved access to the administrative records and audio recordings will lessen the need for future users and archivists to rely on real-time listening or familiarity with the original project.

23 “This Is My Annual Report,” Donnalee Lindberg to Marion Watson, August 23, 1974, Folder: Annual Report 1973-1974, Box 83, University of Minnesota Radio and Television Broadcasting records, ua01039, University Archives, University of Minnesota, Twin Cities. 
Leveraging the tools built within repositories and media players can further supplement the metadata and extend access to the content. Automatic speech recognition (ASR) software creates machine-generated captioning that provides the basis for transcripts. Ultimately, these transcripts can be made available through the player for download and may also be included in the JSON file associated with each item record and distributed through the repository's API. Sonia Yaco notes that ASR-like technology "could help us increase the speed of the appraisal of sound material and provide better intellectual access to potential researchers." ${ }^{24}$ It would assist in the appraisal of medium specificity, further enrich the available metadata for discovery, and lessen the dependence on real-time listening.

\section{Access and use}

The scope of radio collections is their true value and signal their future use. For the KUOM collection, the audio recordings span 50 years. The news coverage, interviews, and recorded conversations touch on nearly every major public policy issue including war, nuclear energy, environmental issues, civil rights, gay and women's liberation movements, religious freedom, and national and international politics. Finding aids provide researchers contextualized descriptions for these topics in the administrative records and audio recordings. Item-level metadata renders actionable information to successfully compete for digitization grants. Digital access to individual recordings demonstrates the rich informational content available through these non-textual archival resources. The availability of these resources enables the repurposing of content and context into new creative applications and new modes of delivery.

\section{Research value}

The ability to have the digitally reformatted audio recordings available online means that individuals can find and use the resources without the mediation of the archivist. Through a word of mouth discussion of the use of audio recordings, an archivist at another repository described how students in a graduate-level social work class were using a series of recordings from the KUOM radio program Breaking the Silence: Voices on Battered

\footnotetext{
${ }^{24}$ Sonia Yaco, "The Potential for Use of Voice Recognition Software in Appraisal and Transcription of Oral History Tapes," ARSC Journal 38, no. 2 (Fall 2007): 222.
} 
Women. The program consisted of eleven episodes that feature interviews with women who have experienced violence and speak as subject-experts. ${ }^{25}$ The graduate students were able to use the recordings independently of the collection and the archives yet within the context of their classroom and learning environment. The use of these audio recordings in this example is a further refinement of the "in the flow" concept of positioning the library "in the user environment and not expect the user to find their way to the library environment." ${ }^{26}$ Other steps taken to place the digital recordings in the user's environment include sharing metadata with aggregating services such as the Digital Public Library of America (DPLA) and development of a REST API service designed to allow for metadata harvesting and to integrate the content into other services.

The administrative records and textual program files described in the online finding aid also account for significant interest in the collection. As an educational radio station, KUOM served as a major media outlet for the University as well as the Upper Midwest for nearly seventy years. As such, the KUOM collection contains unique documentation of people and events not found in other University records or other archival repositories. In 2013, the UMN Archives received a question asking for information about students who participated as Freedom Riders, activists that challenged Jim Crow laws in the South that maintained segregated interstate bus travel, in the summer of 1961. Archives staff were able to locate two press releases that pointed to a special radio broadcast Six Rode South that aired on August 10, 1961; interviewing three University of Minnesota students who traveled to Jackson, Mississippi, and were subsequently arrested and jailed. At the time of the researcher's request, no finding aid existed for the KUOM collection and no list was available to determine if a recording of the broadcast existed. In 2019, archives staff received a similar request. For this inquiry, staff were able to locate a folder for the program Six Rode South in the administrative records which contains newspaper clippings about the students as well as a transcript of the special report (Figure 3). Though no recording of the broadcast was found in the audio inventory to listen to, the additional information found in the clippings and transcript

\footnotetext{
${ }^{25}$ University of Minnesota News Service, "U of M Public Radio to Broadcast Series on Battered Women, March 25, 1987," Press Releases, January - June 1987. Accessed March 18, 2020. http://hdl.handle.net/11299/52012.

${ }^{26}$ Lorcan Dempsey, "In the Flow," Lorcan Dempsey's Weblog on Libraries, Services, and Networks, June 24, 2005. Accessed March 18, 2020. http://orweblog.oclc.org/archives/000688.html.
} 
satisfied the user's request, unlike the previous question received before the collection was processed.

\section{Scripts and newspapers clippings for "Six Rode South" program about Minnesota "freedom riders", 1961 \\ Scope and Contents \\ From the subgroup: A special report on Minnesota freedom riders broadcast by KUOM. Presented interviews with three of the "Freedom Riders," Zev Aelony, Clare O'Connor, and Eugene Uphoff, who discussed their reasons for becoming "freedom riders," their treatment in jail and what the movement has accomplished. Program produced by Randy Anderson. Interviews and narration by Dick Lyon and Dick Stevens. - University News Service \\ Dates \\ 1961}

Figure 3. Scope and contents note for the special broadcast radio report Six Rode South.

Text for the descriptive note was copied from a contemporaneous press release announcing the program since an audio recording wasn't available. Courtesy UMN Libraries.

\section{Podcasting}

To promote the collection and the newly available digitally reformatted program recordings, the UMN Archives began an in-house produced podcast, $U$ of $M$ Radio on Your Historic Dial. ${ }^{27}$ It leveraged the recently available capacity to research the processed administrative records paired with the newly available digital audio content and matched it with a similar platform - podcasting. Archives staff produced three separate seasons. Season one highlighted the variety of programs available in the collection, from Minnesota School of the Air programs for in-school listeners to public affairs lectures for adult audiences. The second season highlighted a Minnesota School of the Air radio program, Look What We Found, that provided a "field trip in sound" through on-the-spot

\footnotetext{
27 The podcast and companion blog posts are available at https://www.continuum.umn.edu/category/radio/. Podcast episodes were researched, written, and voiced by UMN Archives staff: Karen Obermeyer-Kolb, Hannah O’Neill, and Rebecca Toov. All podcast episodes were produced with the assistance of Mark Engebretson, Director of Communications, University of Minnesota Libraries.
} 
interviews recorded at locations in Minnesota. Similarly, the third season, Women on the Air, provided a contextual introduction and then the full radio program so that it retained its primacy as a document. Episodes are linked to companion blog posts on the University of Minnesota Libraries website that features the episode script; images of primary source material from the administrative records, and transcribed text of original recordings. Twenty-three episodes and counting, the podcast aims to reimagine historic radio in new contexts - to engage new listeners, and to encourage the use of educational radio as a primary source.

\section{Conclusion}

Within four years, the unprocessed KUOM collection went from sitting in a twenty-year backlog with no online description or physical access points to a processed collection of 160 cubic feet of administrative records and 508 trays of audio recordings with nearly 5,000 audiotapes digitized. In 2019 , the collection placed in the top $1 \%$ of the most consulted finding aids for the UMN Archives. The popularity of the online collection guide and increasing use of the collection by archives staff and researchers is a testament to the value of radio history. As a medium and as an educational tool, radio allowed for the sharing of content in a way that was not possible before its development and continues to be of value to an international community of scholars researching the role radio played in daily life and how it helped shape the understanding of an ever-changing twentieth century.

To get to this point, however, requires an effort that must balance time, resources, and projected outcomes. While item-level metadata is advocated for as "increasingly important for preservation, both in terms of knowing what you have and planning for reformatting," it is not the only professional approach. ${ }^{28}$ In the last five years, professional practices are cautioning against the item-level description of most audiovisual collections. The Archives of American Art's Guidelines for Processing Collections with Audiovisual Material advises "against certain common default practices for arranging and describing audiovisual material, such as including detailed technical specifications in archival description, arranging all the audiovisual material in a mixed media collection by format,

\footnotetext{
${ }^{28}$ Anthony Cocciolo, Moving Image and Sound Collections for Archivists (Chicago: Society of American Archivists, 2018), 33.
} 
and describing audiovisual media at the item level." 29 Therefore, item-level description must be based on demonstrable business reasons to satisfy the Greene and Meissner approach and to justify the professional effort. The item-level description of the KUOM audio recordings was not a common default practice. It was purposeful in its goal to aid users in discovering content that was hidden from view. It allowed for the metadata to be structured, sharable, and discoverable via other platforms. It provided much needed contextual and technical information for future planning in managing, preserving, and making the collection available through digital reformatting. And, it would not have been possible in an expedited manner without access to the minimally processed administrative records that brought clarity and context to the individual recordings.

The revised "Statement of Principles" proposed for Describing Archives: A Content Standard (DACS) describes archival description as "a continuous intellectual endeavor" and that "description must be iterative" so that it "continually reflects deeper understandings of agents, records, activities, and the relationships between them." ${ }^{30}$ Educational radio had a democratizing effect. It reflected the people, communities, and perspectives not typically associated with a university. These individuals and relationships surface through iterative archival description. Archives and archivists who hold campus-based radio collections can manage what needs to be managed in the aggregate and can iteratively describe that which is necessary to meet user needs, improve discoverability for collections, and better reflect the community represented in the archival materials.

\footnotetext{
${ }^{29}$ Archives of American Art, Guidelines for Processing Collections with Audiovisual Material. Accessed March 18, 2020. https://www.aaa.si.edu/documentation/guidelines-for-processing-collections-withaudiovisual-material.

30 "Statement of Principles for the proposed DACS revision." Accessed March 18, 2020. https:/github.com/saa-tsdacs/dacs/blob/1fcf9c4ad2888384d2664bf998e1474b44d84697/statement_of_principles.md.
} 